\title{
EFEKTIVITAS PRINSIP REDUNDANSI DALAM PRESENTASI PERKULIAHAN
}

\author{
Adriani Halim; Agustinna Yosanny; Andreas Soegandi \\ Computer Science Department, School of Computer Science, Binus University \\ Jl. K.H. Syahdan No. 9, Palmerah, Jakarta Barat 11480 \\ izark@binus.edu
}

\begin{abstract}
The purpose of this study is to study the application of redundancy principles by Richard Mayer on learning material used in class presentation. The principles are applied during the learning material development, using PowerPoint as the learning medium. The result of this study showes that the application of redundancy principle on learning material development provides positive result in helping students' understanding during teacher's presentation.
\end{abstract}

Keywords: redundancy principles, presentation, learning material, PowerPoint

\begin{abstract}
ABSTRAK
Penelitian ini bertujuan untuk mengetahui apakah prinsip redundansi pada pembelajaran multimedia oleh Richard Mayer juga berlaku dalam presentasi perkuliahan di mana prinsip tersebut akan diterapkan dalam pembuatan materi presentasi untuk perkuliahan. Pembuatan materi perkuliahan ini menggunakan PowerPoint sebagai medium pembelajaran. Hasil dari penelitian ini menunjukkan bahwa penerapan prinsip redundansi dalam pembuatan materi perkuliahan memberikan hasil yang positif dalam membantu pelajar untuk menyerap materi pembelajaran tersebut selama perkuliahan.
\end{abstract}

Kata kunci: prinsip redundansi, pembelajaran multimedia, presentasi, PowerPoint 


\section{PENDAHULUAN}

Berbagai macam strategi pembelajaran seperti demonstrasi, tutorial, diskusi kelompok, simulasi, dan lain-lain dapat digunakan untuk mencapai tujuan pembelajaran. Namun dalam kegiatan pendidikan tingkat atas seperti di universitas, masih sering dijumpai penerapan strategi pembelajaran dalam bentuk presentasi. Presentasi sebenarnya merupakan salah satu strategi yang telah lama digunakan dalam pembelajaran terutama di kegiatan pendidikan tingkat atas. Seperti strategi pembelajaran lainnya, presentasi mempunyai sisi positif dan negatif. Presentasi merupakan strategi pembelajaran satu arah dan tidak ada interaksi langsung antara pelajar dan pengajar, akan tetapi strategi ini dapat diterapkan pada pelajar dengan jumlah banyak dan menampilkan informasi yang sama untuk semua pelajar (Newby, 2000). Sisi positif presentasi ini membuat strategi pembelajaran ini masih banyak digunakan dalam pembelajaran di universitas walaupun strategi pembelajaran yang satu arah ini dapat membuat bosan pelajar karena tidak adanya interaksi.

Efektif atau tidaknya strategi presentasi ini dalam pembelajaran dipengaruhi oleh pengajar yang melakukan presentasi, materi pembelajaran yang dipresentasikan, dan juga desain presentasi materi tersebut. Pada jaman tahun 1980an, materi pembelajaran masih menggunakan medium papan tulis dan kapur. Seiring perkembangan jaman, materi pembelajaran mulai dipresentasikan menggunakan kertas transparansi dan overhead projector dan kemudian beralih menggunakan PowerPoint atau perangkat lunak sejenis sebagai mediumnya. Jones (2003) menyatakan bahwa penggunaan PowerPoint yang sesuai dapat meningkatkan pembelajaran. Dia juga menjabarkan berbagai penyalahgunaan PowerPoint dalam kegiatan pembelajaran seperti menggunakan terlalu banyak teks dan gambar, memasukkan suara yang mengganggu, dan penggunaan media yang tidak sesuai.

Dengan berkembangnya penggunaan berbagai media dalam satu medium, Mayer (2009) menjabarkan teori dan juga berbagai prinsip pembelajaran multimedia yang dapat diterapkan dalam perancangan materi pembelajaran agar dapat meningkatkan efektivitas pembelajaran.

Teori kognitif untuk pembelajaran multimedia dan prinsip multimedia yang dikemukakan oleh Mayer (2009) ini telah banyak diujicoba efektivitasnya dalam berbagai bidang ilmu baik secara langsung maupun melalui e-learning. Aldalalah dan Fong (2010) meneliti efek dari prinsip modalitas dan redundansi dalam pembelajaran teori musik dan hasil penelitian mereka membuktikan efektivitas prinsip modalitas dan redundansi. Tabbers, Martens, dan Van Merrienboer (2004) meneliti efek prinsip modalitas dan signaling di sebuah ruang kelas. Sabet dan Shalmani (2010) meneliti efek prinsip modalitas pada pembelajaran bahasa dan menyimpulkan bahwa prinsip modalitas tidak berlaku jika tujuan pembelajaran adalah untuk mengingat kosakata. Crooks, White, Srinivasan, dan Wang (2008) meneliti efek prinsip pendampingan (contiguity) dan menyatakan bahwa prinsip pendampingan secara temporal merupakan strategi yang efektif dalam pembelajaran peta berbasiskan komputer.

Penelitian Kalyuga, Chandler, dan Sweller (2004) juga mendukung teori redundansi. Mereka menyimpulkan bahwa presentasi dengan medium suara dan teks tertulis yang bersamaan melebihi kemampuan working memory yang dipunyai pelajar sehingga kedua medium tersebut tidak dapat diproses dengan baik oleh pelajar. Namun Mayer, Heiser, and Lonn (2001, p.196) berpendapat bahwa prinsip mulmedia ini tidak boleh diterima bulat-bulat. Mereka mengakui bahwa PowerPoint yang menggunakan teks dalam bentuk tulisan di layar dan juga dipresentasikan secara lisan dapat menjadi pembelajaran yang efektif.

Berdasarkan pembahasan di atas, penelitian kali ini akan menjabarkan penerapan prinsip redundansi dalam pembuatan materi pembelajaran dengan menggunakan PowerPoint. Dengan menerapkan prinsip pembelajaran multimedia Mayer pada pembuatan materi pembelajaran, 
diharapkan terlihat adanya peningkatan efektivitas pembelajaran yang menggunakan strategi pembelajaran presentasi.

\section{METODE}

Penelitian ini dimulai dengan studi kepustakaan mengenai prinsip pembelajaran multimedia Mayer dan teori-teori yang berkaitan. Penelitian ini terdiri dari beberapa tahap, dimulai dari pembuatan materi pembelajaran, kemudian membentuk grup penelitian. Data yang didapat dari grup penelitian ini akan dianalisis untuk menentukan hasilnya. Secara ringkas, tahap-tahap penelitian ditampilkan pada Gambar 1 berikut ini.

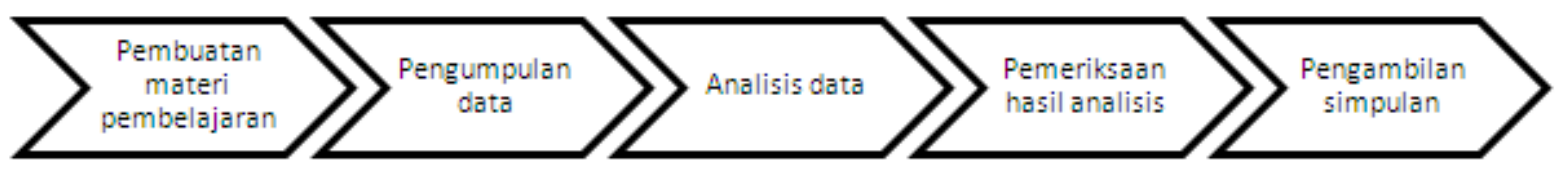

Gambar 1. Tahap-tahap Penelitian

\section{Pembuatan Materi Pembelajaran}

Materi pembelajaran yang digunakan adalah materi perkuliahan kelas Sistem Multimedia di Binus University. Materi ini dibuat dengan PowerPoint dalam dua versi. Versi pertama lebih banyak menggunakan gambar dan grafik sedangkan penjelasan dilakukan secara lisan oleh pengajar. Versi kedua menyertakan tambahan teks untuk menekankan materi yang dipresentasikan pengajar secara lisan. Pembuatan materi pembelajaran ini mengikuti prinsip-prinsip pembelajaran multimedia yang dikemukakan oleh Mayer (2005, p117-211) yang kemudian dibahas lebih lanjut bersama Clark (2008). Berikut ini adalah ringkasan dari prinsip-prinsip yang dikemukakan: (1) prinsip multimedia, yaitu menggunakan teks dan grafik untuk penyampaian materi pembelajaran; (2) prinsip perdampingan (contiguity), yaitu menempatkan teks pada posisi yang dekat dengan grafik yang berkaitan; (3) prinsip modalitas, yaitu lebih baik menggunakan suara untuk menyampaikan teks daripada tulisan tertulis; (4) prinsip redundansi, yaitu menjelaskan gambar dengan suara atau tulisan tertulis, tetapi tidak keduanya; (5) prinsip koherensi, di mana menambahkan materi tambahan yang tidak berhubungan dengan tujuan pembelajaran dapat menghambat proses pembelajaran; (6) prinsip personalisasi, di mana lebih baik menggunakan kalimat percakapan daripada kalimat formal dalam proses pembelajaran; (7) prinsip segmentasi, yaitu lebih baik membagi-bagi materi pembelajaran kedalam beberapa bagian.

Selain penerapan prinsip pembelajaran multimedia, pembuatan dan presentasi materi pembelajaran ini juga berusaha menghindari penyalahgunaan PowerPoint untuk proses pembelajaran seperti yang dijabarkan oleh Jones (2003), yaitu: (1) memasukkan terlalu banyak detil sehingga pelajar tidak perlu menyimak ataupun hadir (kalau mereka akan mendapatkan filenya nanti) dalam presentasi tersebut; (2) terlalu banyak warna merah dan hijau; (3) terlalu banyak teks sehingga susah dibaca; (4) terlalu banyak grafik; (5) ada bunyi-bunyi dan transisi setiap slide yang menganggu; (6) penggunaan multimedia yang tidak cocok; (7) tidak menggunakan kelebihan PowerPoint dalam membuat presentasi; (8) kecenderungan untuk presentasi dengan cepat.

\section{Pengumpulan Data}

Para responden untuk penelitian ini dipilih secara random dari mahasiswa BINUS University 
yang sedang mengikuti matakuliah Sistem Multimedia. Para responden dibagi menjadi dua kelompok di mana kelompok pertama mendapat presentasi materi Sistem Multimedia yang menggunakan grafik dan gambar tanpa teks tertulis, sedangkan kelompok kedua mendapat presentasi yang menggunakan grafik beserta tambahan teks yang juga dipresentasikan secara lisan. Penelitian ini diadakan dalam ruang kelas dan kedua kelompok responden mendapat materi pembelajaran yang sama tetapi berbeda dalam presentasinya.

Para responden dari kedua grup akan diberikan presentasi materi pembelajaran dan kemudian setelah selesai presentasi, mereka diminta untuk mengerjakan tes yang hasilnya akan digunakan untuk keperluan analisis data penelitian. Sesi pembelajaran ini diadakan sebanyak dua kali dengan menggunakan ruang kelas yang sama pada tiap sesinya.

\section{Analisis Data}

Pada kelompok responden yang diberikan presentasi grafik dan lisan, terdapat 55 responden. Pada kelompok responden yang diberikan presentasi grafik, lisan, dan teks, terdapat 56 responden Sampel data yang didapat dari dua kali hasil tes akan dihitung nilai rata-ratanya per kelompok responden. Sampel data ini bersifat independen karena terdiri dari dua kelompok responden yang berbeda.

\section{HASIL DAN PEMBAHASAN}

Hasil analisis data ini kemudian diuji menggunakan metode Mann-Whitney satu sisi dengan hipotesa sebagai berikut:

$$
\begin{aligned}
& \mathrm{H}_{0}=\mathrm{n}_{1} \leq \mathrm{n}_{2} \\
& \mathrm{H}_{1}=\mathrm{n}_{1}>\mathrm{n}_{2}
\end{aligned}
$$

di mana $n_{1}$ adalah nilai responden yang diberikan presentasi grafik dan lisan dan $n_{2}$ adalah nilai responden yang diberikan presentasi grafik, lisan, dan teks. Tabel 1 menunjukkan hasil nilai rata-rata tiap responden di setiap kelompok responden.

Tabel 1

Rata-rata Hasil Tes

\begin{tabular}{ccc}
\hline No. & Grafik+Lisan & Grafik+Lisan+Teks \\
\hline 1 & 90.5 & 75.5 \\
\hline 2 & 77.9 & 86.2 \\
\hline 3 & 71.4 & 85.8 \\
\hline 4 & 87.3 & 71.2 \\
\hline 5 & 89.5 & 51.5 \\
\hline 6 & 95.6 & 84 \\
\hline 7 & 91.8 & 73.5 \\
\hline 8 & 79.9 & 60.8 \\
\hline 9 & 84.6 & 53.9 \\
\hline 10 & 91.9 & 73 \\
\hline 11 & 75.2 & 52.6 \\
\hline 12 & 61.9 & 53.1 \\
\hline
\end{tabular}




\begin{tabular}{|c|c|c|}
\hline 13 & 77.4 & 72.6 \\
\hline 14 & 87 & 62.6 \\
\hline 15 & 84 & 73.8 \\
\hline 16 & 77.7 & 74.3 \\
\hline 17 & 79.9 & 38.7 \\
\hline 18 & 83.5 & 34.2 \\
\hline 19 & 63.8 & 77.9 \\
\hline 20 & 73.8 & 48.1 \\
\hline 21 & 75.5 & 82.6 \\
\hline 22 & 61.3 & 26.4 \\
\hline 23 & 70 & 63.6 \\
\hline 24 & 61.2 & 31.5 \\
\hline 25 & 83.7 & 76.2 \\
\hline 26 & 75.6 & 73.7 \\
\hline 27 & 77.1 & 64.3 \\
\hline 28 & 58.1 & 75.2 \\
\hline 29 & 50.8 & 77.1 \\
\hline 30 & 89.2 & 63 \\
\hline 31 & 81.8 & 67.7 \\
\hline 32 & 71.3 & 89 \\
\hline 33 & 74.5 & 57.5 \\
\hline 34 & 91 & 67.3 \\
\hline 35 & 91.4 & 19 \\
\hline 36 & 69.4 & 80.8 \\
\hline 37 & 76.3 & 37.3 \\
\hline 38 & 59 & 73.7 \\
\hline 39 & 86.4 & 50.5 \\
\hline 40 & 66.7 & 50.5 \\
\hline 41 & 75.4 & 83.8 \\
\hline 42 & 57.3 & 84.8 \\
\hline 43 & 55.4 & 64.5 \\
\hline 44 & 36.7 & 42.6 \\
\hline 45 & 83.3 & 35 \\
\hline 46 & 55.4 & 47.3 \\
\hline 47 & 68.7 & 27.9 \\
\hline 48 & 42.5 & 78.7 \\
\hline 49 & 73.8 & 63.6 \\
\hline 50 & 84.6 & 79 \\
\hline 51 & 71.4 & 25 \\
\hline 52 & 59.6 & 77.6 \\
\hline 53 & 64.8 & 40.6 \\
\hline
\end{tabular}




\begin{tabular}{lll}
\hline 54 & 67.6 & 78.6 \\
\hline 55 & 58.8 & 46.2 \\
\hline 56 & & 40.4 \\
\hline
\end{tabular}

Hasil data di atas diuji dengan menggunakan metode Mann-Whitney satu sisi. Hasilnya dapat dilihat pada Tabel 2 berikut ini.

Tabel 2

Hasil Uji Mann-Whitney

\begin{tabular}{llrrr}
\hline \multicolumn{5}{c}{ Ranks } \\
group & N & & Mean Rank & Sum of Ranks \\
\hline \multirow{2}{*}{ Nilai } & Grafik + lisan & 55 & 66.43 & 3653.50 \\
\cline { 2 - 5 } & Grafik + lisan + teks & 56 & 45.76 & 2562.50 \\
\cline { 2 - 5 } & Total & 111 & & \\
\hline
\end{tabular}

Test Statistics ${ }^{\mathrm{a}}$

\begin{tabular}{lr}
\hline & \multicolumn{1}{c}{ Nilai } \\
\hline Mann-Whitney U & 966.500 \\
\hline Wilcoxon W & 2562.500 \\
\hline Z & -3.383 \\
\hline Asymp. Sig. (2-tailed) & .001 \\
\hline
\end{tabular}

a. Grouping Variable: group

Hasil uji Mann-Whitney memberikan nilai 0.001 untuk ujian dua sisi (2-tailed). Untuk ujian satu sisi, nilai ini dibagi dua menjadi 0.0005 di mana nilai ini lebih kecil dari tingkat signifikansi $(\alpha)=$ 0.05. Karena nilai ini lebih kecil dari 0.05 , hipotesa $\mathrm{H}_{0}=\mathrm{n}_{1} \leq \mathrm{n}_{2}$ ditolak dan $\mathrm{H}_{1}=\mathrm{n}_{1}>\mathrm{n}_{2}$ diterima yaitu nilai responden yang diberikan presentasi dengan menggunakan grafik dan lisan lebih tinggi daripada nilai responden yang diberikan presentasi dengan menggunakan grafik, lisan, dan teks.

\section{PENUTUP}

Analisis data yang telah dilakukan menunjukkan bahwa penerapan prinsip redundansi dari teori Mayer memberikan hasil positif dalam peningkatan efektivitas pembelajaran yang menggunakan strategi pembelajaran presentasi. Akan tetapi, penulis menyadari bahwa penerapan prinsip redundansi ini belum tentu berlaku untuk semua materi pelajaran. Plass (2005) mengemukakan pendapat bahwa ada kemungkinan prinsip redundansi dan modalitas yang dikemukakan Mayer tidak berlaku untuk pembelajaran bahasa. Perlu adanya penelitian lanjut untuk mengetahui apakah bagaimana efektivitas prinsip redundansi ini terhadapat materi pelajaran di bidang yang lainnya. 


\section{DAFTAR PUSTAKA}

Aldalalah, O. A., \& Fong, S. F. (2010). Effects of modality and redundancy principles on the learning and attitude of a computer-based music theory lesson among jordanian primary pupils. International Education Studies, 3(3), 52-64. Diakses dari http://search.proquest.com/docview/821816039?accountid=31532.

Clark, R. C. (2008). E-Learning and the Science of Instruction: Proven Guidelines for Consumers and Designers of Multimedia Learning. San Fransisco: Pfeiffer.

Crooks, S., White, D., Srinivasan, S., \& Wang, Q. (2008). Temporal, but not spatial, contiguity effects while studying an interactive geographic map. Journal of Educational Multimedia and Hypermedia, 17(2), 145-169. Diakses dari http://search.proquest.com/docview/205853778?accountid=31532.

Jones, A.M. (2003) The Use and Abuse of PowerPoint in Teaching and Learning in the Life Sciences: A Personal Overview. Bioscience Education E-journal, 2-3. Diakses dari http://www.bioscience.heacademy.ac.uk/journal/vol2/beej-2-3.aspx

Kalyuga, S., Chandler, P., \& Sweller, J. (2004). When Redundant On-Screen Text In Multimedia Technical Instruction Can Interfere With Learning. Human Factors, 46(3), 567-81. Diakses dari http://search.proquest.com/docview/216460923?accountid=31532.

Mayer, R. E, (Ed.). (2005). The Cambridge Handbook of Multimedia Learning. Cambridge: The Press Syndicate of the University of Cambridge.

Mayer, R. E., Heiser, J., \& Lonn, S. (2001). Cognitive constraints on multimedia learning: When presenting more material results in less understanding. Journal of Educational Psychology, 93(1), 187-198.

Newby, T. J., Stepich, D. A., Lehman, J. D. \& Russell, J. D. (2000). Identifying methods and media for learning. Instructional Technology for teaching and learning (Ch 5, 90-114). New Jersey: Prentice Hall..

Plass, J. L., dan Jones, L. C. (2005). Multimedia Learning in Second Language Acquisition dalam Mayer (Ed.). The Cambridge Handbook of Multimedia Learning. New York: Cambridge University Press.

Sabet, M. K., \& Shalmani, H. B. (2010). Visual and spoken texts in MCALL courseware: The effects of text modalities on the vocabulary retention of EFL learners. English Language Teaching, 3(2), 30-36. Diakses dari http://search.proquest.com/docview/838891152?accountid=31532

Tabbers, H. K., Martens, R. L., \& Van Merrienboer, J.J.G. (2004). Multimedia instructions and cognitive load theory: Effects of modality and cueing. British Journal of Educational Psychology, 74(00070998), 71-82. Diakses dari http://search.proquest.com/docview/216959067?accountid=31532 